\title{
Efeito de produtos alternativos e de fungicidas no controle do míldio da videira
}

\author{
Regina Ceres Torres da Rosa ${ }^{1}$, Vanildo Alberto Leal Bezerra Cavalcanti ${ }^{1}$, Rildo Sartori Barbosa Coelho ${ }^{1}$ José do \\ Egito de Paiva².
}

1'Laboratório de Fitopatologia, IPA, Bongi, 50761-000, Recife-PE, e-mail: reginactrosa@ gmail.com; vanildo@ipa.com.br ; sartori@ hotlink.com.br ${ }^{2}$ Departamento de Tecnologia Rural, UFRPE, Dois Irmãos, 52171-900, Recife-PE, e-mail: egito@ ufrpe.br Autor para correspondência: Regina Ceres Torres da Rosa. reginactrosa@gmail.com Data de chegada: 10/12/2005. Aceito para publicação em: 04/06/2008

\section{RESUMO}

Rosa, R.C.T., Cavalcanti, V.A.L.B., Coelho, R.S.B. \& Paiva, J.E. Efeito de produtos alternativos e de fungicidas no controle do míldio da videira. Summa Phytopathologica, v.34, n.3, p.256-258, 2008

O efeito de Agro-Mos e óleo de Nim no controle de Plasmopara viticola foi avaliado em videiras da variedade 'Isabel'. Os resultados obtidos demonstraram que tratamentos (Agro-Mos + Crop-set e Fungicida, Óleo de Nim e Fungicida, Agro-Mos + Crop-set e Óleo de Nim, e fungicida) não diferiram estatisticamente da testemunha, com relação à severidade e AACPD do míldio da videira. Quanto à eficiência de controle o Agro-Mos + Crop-set e Fungicida, Agro-Mos + Crop-set e Óleo de Nim, e Óleo de Nim e Fungicida foram capazes de reduzir a severidade da doença em $19,25 \%, 17,39 \%$ e $16,15 \%$, respectivamente. $\mathrm{O}$ efeito dos produtos na qualidade dos frutos de uva, tanto para o $\mathrm{pH}$ quanto para os SST ('Brix) não diferiu significativamente em relação à testemunha. O tratamento Agro-Mos + Crop-set e Fungicida obteve o maior teor de ATT (g/ L), contudo não diferiu estatisticamente dos tratamentos Óleo de Nim e Fungicida, e Fungicida.

Palavras-Chave Adicionais: Plasmopara viticola, Vitis labrusca, Nim, controle, resistência

\section{ABSTRACT}

Rosa, R.C.T., Cavalcanti, V.A.L.B., Coelho, R.S.B. \& Paiva, J.E. Effect of alternative products and fungicides in the control of downy mildew in Vitis labrusca. Summa Phytopathologica, v.34, n.3, p.256-258, 2008

The effect of Agro-Mos and Nim oil in the control of Plasmopara viticola was evaluated on grape variety 'Isabel'. No significant differences in both severity and AACPD were found among treatments. The control efficiency of Agro-Mos + Crop-set and Fungicide, Agro-Mos + Crop-set and Nim oil, and Nim oil and Fungicide reduced the severity in $19,25 \%, 17,39 \%$ and $16,15 \%$, respectively. In relation to effect the treatments on juice quality, there was not significant difference in the $\mathrm{pH}$ and SST ( ${ }^{\circ}$ Brix). The treatment AgroMos + Crop-set and Fungicide induced higher ATT (g/ L) level, but not significant different from Nim oil and Fungicide, and Fungicide.

Additional keywords: Plasmopara viticola, Vitis labrusca, Nim, control, resistance

Plasmopara viticola (Berk. \& Curt.) Curt. \& de Toni é o agente causal do míldio da videira (Vitis spp.), que afeta grande parte das áreas produtoras de uva do mundo, provocando diminuição da quantidade e qualidade dos frutos e consideráveis perdas de produção, devido à infecção que ocorre nos ramos e flores antes, durante e depois do florescimento (8). Essa doença torna-se mais séria em anos com elevada precipitação pluviométrica, alta umidade relativa do ar e longos períodos de umidade sobre as folhas e frutos, com perdas que podem atingir $100 \%$ da produção de um vinhedo (7). A cultivar 'Isabel' de Vitis labrusca L., predomina no vale do Siriji, em Pernambuco, sendo bastante susceptível a $P$. viticola. Em relação ao desenvolvimento, produção e qualidade da uva, existem poucas informações sobre a magnitude dos efeitos desse patógeno nessa cultura. O controle do míldio, realizado pelo uso exclusivo de fungicidas, não tem proporcionado resultados satisfatórios. Por outro lado, a redução ou eliminação de agrotóxicos no controle das doenças é uma necessidade econômica e ambiental. A Produção Integrada de Frutas - PIF para o setor agrícola tem proposto normas para segurança alimentar estabelecendo regras rígidas que leva em consideração os resíduos de agroquímicos. Considerando esses fatos se faz necessário à utilização de métodos alternativos para o controle dessa doença, assim o presente trabalho teve como objetivos verificar a eficácia da aplicação de Agro$\mathrm{Mos}^{\circledR}+$ Crop-set $^{\circledR}$ e Óleo de Nim no controle de $P$. viticola, em plantios comerciais de V. labrusca cultivar 'Isabel' e avaliar se os indutores afetam o potencial de produção e a qualidade da uva produzida.

O experimento foi realizado em área de produção de V. labrusca, cultivar 'Isabel', localizada no município de São Vicente Férrer - PE, no período de abril a agosto de 2005. As aplicações dos produtos foram realizadas quinzenalmente, utilizando-se pulverizador costal, 20 dias após a brotação das videiras, perfazendo um total de quatro aplicações, com os seguintes produtos: 1- Agro-Mos (Saccharomyces cerevisae 1026) + Crop-set (fertilizante a base de Manganês, Cobre e Ferro) (1 mL.L $\left.\mathrm{L}^{-1} ; 0,3 \mathrm{~mL} . \mathrm{L}^{-1}\right)$ intercalado com um rodízio de fungicidas usados habitualmente pelo agricultor (metalaxyl e tebuconazole adicionados com propineb) nas dosagens indicadas pelos fabricantes; 2- Óleo de Nim (azadirachtina, salanina, nimbina, nimbidina, meliantriol, 
Quadro 1 - Efeito de indutores abióticos na severidade e na área abaixo da curva de progresso da doença - AACPD do míldio da videira, no estado de Pernambuco

\begin{tabular}{|c|c|c|c|c|}
\hline \multirow{2}{*}{ Tratamento } & \multicolumn{4}{|c|}{ Parâmetro } \\
\hline & Severidade média $^{1}$ & Severidade $^{2}$ & AACPD & Eficiência de Controle \\
\hline Agro-Mos + Crop-set e Fungicida & $1,90 \mathrm{a}$ & $3,90 \mathrm{a}$ & $12,79 \mathrm{a}$ & $(\%)^{3}$ \\
\hline Óleo de Nim e Fungicida & $2,01 \mathrm{a}$ & $3,99 \mathrm{a}$ & $13,55 \mathrm{a}$ & 19,25 \\
\hline Agro-Mos + Crop- set e Óleo de Nim & $2,05 \mathrm{ab}$ & $4,05 \mathrm{a}$ & $13,82 \mathrm{a}$ & 17,39 \\
\hline Fungicida & $2,02 \mathrm{a}$ & $4,32 \mathrm{a}$ & $13,97 \mathrm{a}$ & 16,15 \\
\hline Testemunha & $2,36 \mathrm{~b}$ & $4,83 \mathrm{a}$ & $16,03 \mathrm{a}$ & 10,53 \\
\hline$\overline{\mathrm{CV}}(\overline{\%})$ & 17,79 & 10,99 & $\overline{14}, \overline{79}$ & - \\
\hline
\end{tabular}

${ }^{1}$ Média das 3 repetições de cada tratamento nas sete avaliações. Em cada coluna média seguida de letras distintas são diferentes entre si, ao nível de 5\% de probabilidade pelo teste de Tukey.

${ }^{2}$ Média de 3 repetições uma semana após a ultima aplicação com o indutor. Em cada coluna média seguida de letras distintas são diferentes entre si, ao nível de $5 \%$ de probabilidade pelo teste de Tukey.

${ }^{3}$ As análises foram realizadas utilizando a formula de Abbott (01).

Quadro 2 - Efeito do míldio da videira, sobre as características analíticas do mosto da Vitis labrusca cv. Isabel, em diferentes tratamentos

\begin{tabular}{|c|c|c|c|c|}
\hline \multirow{2}{*}{ Tratamento } & \multicolumn{4}{|c|}{ Parâmetro } \\
\hline & $\mathbf{p} \mathbf{H}^{1}$ & SST - ${ }^{o}$ Brix $(\%)^{1}$ & $\operatorname{ATT}(\mathbf{g} / \mathbf{L})^{1}$ & AT $(\%)$ \\
\hline Agro-Mos + Crop -set & $3,08 \mathrm{a}$ & $14,43 a$ & $15,1 \mathrm{a}$ & $1,51 \mathrm{a}$ \\
\hline Óleo de Nim & $3,09 \mathrm{a}$ & $14,17 \mathrm{a}$ & $13,8 \mathrm{ab}$ & $1,38 \mathrm{ab}$ \\
\hline Agro-Mos + Crop- set e Óleo de Nim & $3,09 \mathrm{a}$ & $14,27 \mathrm{a}$ & $12,1 \mathrm{bc}$ & $1,21 \mathrm{bc}$ \\
\hline Fungicida & $3,05 \mathrm{a}$ & $13,93 \mathrm{a}$ & $13,8 \mathrm{ab}$ & $1,38 \mathrm{ab}$ \\
\hline Testemunha & $3,16 \mathrm{a}$ & $15,07 \mathrm{a}$ & $10,7 \mathrm{c}$ & $1,07 \mathrm{c}$ \\
\hline$\overline{\mathrm{CV}}(\%)$ & 6,39 & 5,84 & 7,88 & 7,88 \\
\hline
\end{tabular}

${ }^{1}$ Média das 3 repetições de cada tratamento nas sete avaliações. Em cada coluna média seguida de letras distintas são diferentes entre si, ao nível de 5\% de probabilidade pelo teste de Tukey.

${ }^{2}$ Média de 3 repetições uma semana após a ultima aplicação com o indutor. Em cada coluna média seguida de letras distintas são diferentes entre si, ao nível de $5 \%$ de probabilidade pelo teste de Tukey.

${ }^{3}$ As análises foram realizadas utilizando a formula de Abbott (01).

triterpenos e limonoides) (1,0\%) intercalado com o mesmo rodízio de fungicidas citado no item 1; 3- Agro-Mos + Crop-set intercalado com óleo de Nim (1,0\%); 4- Rodízio de fungicidas (testemunha relativa); e 5- Testemunha absoluta.

As avaliações foram efetuadas em 50 folhas da planta central de cada parcela, que era constituída de nove plantas. Em todas as áreas, as amostragens, para avaliação da doença, foram iniciadas sete dias após a primeira aplicação dos produtos, sendo realizada semanalmente, totalizando sete avaliações. No experimento foi utilizado o delineamento estatístico em blocos ao acaso, constituído de cinco tratamentos e três repetições. Foram analisadas as variáveis: Severidade da doença e Área Abaixo da Curva de Progresso da Doença - AACPD (12). A severidade foi estimada com o auxílio de escala diagramática, descrita por Azevedo (1). As médias da severidade e AACPD foram comparadas pelo teste de Tukey.

$O$ efeito de cada tratamento sobre a qualidade do suco foi determinado através do $\mathrm{pH}$, ácidos totais tituláveis (ATT) e sólidos solúveis totais (SST, expresso com ${ }^{0}$ Brix). Foram retirados e conduzidos ao laboratório três cachos por planta, e dos mesmos foram retiradas seis bagas/cacho para efetuar as análises. Esses cachos foram amostrados das partes basal, mediana e apical do ramo principal de cada uma das parreiras centrais, de cada repetição/tratamento. As bagas de cada repetição foram maceradas juntas e o $\mathrm{pH}$ do suco foi mensurado, pelo uso de pHmetro. A concentração dos SST do suco foi medida através de refratômetro. Os ATT, representado pelo ácido tartárico, foi medido pela titulação com $0,1 \mathrm{M} \mathrm{NaOH}$ (6).

Com relação à severidade e AACPD do míldio da videira os resultados demonstram que os tratamentos não diferiram estatisticamente da testemunha (Quadro 1). Observou-se que os tratamentos Agro-Mos + Crop-set e Fungicida, Agro-Mos + Cropset e Óleo de Nim, e Óleo de Nim e Fungicida foram capazes de reduzir a severidade da doença em 19,25\%, 17,39\% e 16,15\%, respectivamente. Diferindo de Rosa et al. (11) que utilizaram BABA, Agro-Mos + Crop-set, Agro-Mos + Crop-set e Codavit, Codavit e Ecolife, o Agro-Mos + Crop-set se destacou dos demais em relação à eficiência de controle para mesma doença com percentuais variando de $37,46 \%$ a $18,57 \%$ nas três áreas estudadas. Um dos fatores que podem ter contribuído para a diferença dos resultados em relação à eficiência de controle da doença pode ser à variação climática tendo em vista os índices pluviométricos médios registrados foram de $221 \mathrm{~mm}$, com amplitude de 143-306 mm no trabalho anterior e de 162,4 mm, com amplitude de 31-447 mm no presente trabalho. Estudos da antracnose em mamão, manga e maracujá, em pós-colheita, com os indutores Agro-Mos e Ecolife proporcionaram reduções significativas na severidade da referida doença $(2,4,5)$. No Quadro 2 observa-se o efeito dos produtos na qualidade dos frutos de uva, tanto para o $\mathrm{pH}$ quanto para os SST ( ${ }^{\circ}$ Brix), não havendo diferença significativa dos tratamentos em relação à testemunha. Os valores médios do $\mathrm{pH}$ e dos SST variaram de 3,08 - 3,16 e 13,93\% - 15,07\%, respectivamente. O tratamento Agro-Mos + Crop-set e Fungicida obteve o maior teor de 
ATT, que foi de $15,1 \mathrm{~g} / \mathrm{L}$, contudo não diferiu estatisticamente dos tratamentos Óleo de Nim e Fungicida, e Fungicida. Reuveni et al. (9) utilizaram o indutor BABA ou a mistura dele com fungicidas, em Vitis vinifera L. cvs. 'Cabernet Sauvignon' e 'Chardonnay', constataram que os mesmos não afetaram o pH, os ATT ou o Brix do mosto. Os valores dos SST para o tratamento com fungicida e dos ATs de todos os tratamentos obtidos, no presente trabalho, não atendem aos padrões de qualidade exigidos pelo Ministério da Agricultura, Pecuária e Abastecimento, que são Brix mínimo de 14\% e AT máximo de 0,9 (3). Apesar dos valores dos SST estarem no mínimo exigido, sabe-se que a maioria das cultivares de V. labrusca apresentam menor potencial de produção de açúcar do que as $V$. vinifera (10), somando-se a isso as condições climáticas desfavoráveis no período de desenvolvimento do experimento.

Os resultados obtidos, neste experimento, apresentaram dados controversos em relação ao trabalho executado anteriormente (11), devido possivelmente às condições climáticas da região, os quais foram diferentes em relação ao índice e a distribuição da pluviosidade, há necessidade de se repetir o estudo na mesma região para consolidação da metodologia utilizada.

\section{AGRADECIMENTOS}

Ao produtor Manuel Vicente da Silva por ceder a área para instalação do experimento e apoio logístico na execução do mesmo.

\section{REFERÊNCIAS BIBLIOGRÁFICAS}

1. Azevedo, L.A.S. Manual de quantificação de doenças de plantas. São Paulo: Luiz Antonio Siqueira de Azevedo, 1997. 114p.

2. Benato, E.A; Sigrist, J.M.M; Hanashiro, M. M.; Magalhães, M.J.M.A.; Binotti, C.S. Avaliação de fungicidas e produtos alternativos no controle de podridões pós-colheita em maracujá ama- relo. Summa Phytopathologica, Botucatu, v. 28, n.4, p.299$304,2002$.

3. Brasil. Instrução Normativa $n^{\circ} 01$, de 7 de janeiro de 2000. Aprova o Regulamento técnico geral para fixação dos padrões de identidade e qualidade para polpa de fruta. Brasília, DF, 7 jan. 2000. Disponível em: < http://oc4j.agricultura.gov.br/agrolegis/do/ consultaLei?op=viewTextual\&codigo $=7777>$. Acesso em: 4 out. 2005.

4. Dantas, S.A.F.; Oliveira, S.M.A.; Bezerra Neto, E.; Coelho, R.S.B.; Silva, R.L.X. Indutores de resistência na proteção do mamão contra podridão pós-colheita. Summa Phytopathologica, Botucatu, v.30, n. 1, p. 77-87, 2002.

5. Dantas, S.A.F.; Tavares, S.C.C. de H.; Oliveira, S.M.A.; Coelho, R.S.B.; Cavalcanti, V.A.L B.; Silva, R.L.X. Indutores abióticos de resistência a patógenos Pós-colheita de manga. Fitopatologia Brasileira, Fortaleza, v.29, supl., p. 52, 2004.

6. Instituto Adolfo Lutz. Normas analíticas do Instituto Adolfo Lutz: métodos químicos e físicos para análise de Alimentos. 3. ed. São Paulo. Instituto Adolfo Lutz, 1985. 317p.

7. Madden, L.V, Ellis, M.A., Lalancette, N., Hughes, G., Wilson, L.L. Evaluation of disease warning system for downy mildew of grapes. Plant Disease, St. Paul, v. 84, n. 25, p.549-554, 2000.

8. Pearson, R.C.; Goheen, A.C. Compendium of grape disease. St. Paul: APS Press, 1988. 93 p.

9. Reuveni, M.; Zahavi, T.; Cohen,Y. Controlling Downy Mildew (Plasmopara viticola) in field-grown grapevine with â-aminobutyric acid (BABA). Phytoparasitica, Rehovot, v.29, n.2, p.1-9. 2001.

10. Rizzon, L.A.; Miele, A.; Meneguzzo, J. Avaliação da uva cv. Isabel para elaboração de vinho tinto. Ciência Tecnologia de Alimentos, Campinas, v.20, n.1, p. 115-121. 2000.

11. Rosa, R.C.T., Coelho, R.S.B., Tavares, S.C.C. de H. \& Cavalcanti, V.A.L.B. Efeito de indutores abióticos na resistência ao míldio em Vitis labrusca. Summa Phytopathologica, Botucatu, v. 33, n.1, p., 2007.

12. Shaner, G.; Finney, R.E. The effect of nitrogen fertilization on the expression of slow-mildewing resistance in knox wheat. Phytopathology, St. Paul, v.67, n.8, p. 1051-1056. 1977. 